\title{
Determinação de Urânio em Amostras de Mexilhões Perna perna Transplantados ao Longo do Litoral de São Paulo, por Análise por Ativação com Nêutrons Epitérmicos (AANE)
}

\author{
D. Seo, ${ }^{1,2^{*}}$ M. G. M. Catharino, ${ }^{1}$ E. G. Moreira, ${ }^{1}$ M. Saiki, ${ }^{1}$ M. B. A. Vasconcellos, ${ }^{1}$ \\ C. D. S. Pereira ${ }^{3}$ \& E.C. P. M. Sousa ${ }^{3}$ \\ ${ }_{2}$ Instituto de Pesquisas Energéticas e Nucleares (IPEN-CNEN/SP), São Paulo, SP, Brasil \\ ${ }_{2}$ Universidade Presbiteriana Mackenzie, São Paulo, SP, Brasil \\ ${ }_{3}$ Laboratório de Ecotoxicologia Marinha, Instituto Oceanográfico, Universidade de São Paulo (IOUSP), São Paulo, SP, Brasil
}

(Received February 6, 2007; Accepted October 10, 2008)

\begin{abstract}
RESUMO
Moluscos bivalves vêm sendo utilizados em estudos de biomonitoração de regiões costeiras, pois são capazes de acumular poluentes. Este trabalho apresenta resultados das determinações de urânio em amostras de mexilhões, da espécie Perna perna (Linnaeus, 1758), transplantados ao longo do litoral norte do Estado de São Paulo. Mexilhões provenientes de um cultivo situado na Praia da Cocanha, Caraguatatuba (controle), foram transplantados em todas as estações do ano para quatro pontos de transplantes: Praia do Engenho d'Água, em Ilhabela; Terminal Almirante Barroso (TEBAR), em São Sebastião; e Ilha das Palmas e Itaipu, na Baía de Santos. Para as determinações de urânio foi utilizada a técnica de análise por ativação com nêu-trons epitérmicos (AANE), e para controle da qualidade dos resultados foram analisados os materiais de referência certificados NIST SRM1566b Oyster Tissue e NIST SRM 1575 Pine Needles. Os resultados obtidos foram concordantes com os valores dos certificados, com percentagens de erro relativos inferiores a 2,2\%, e apresentaram boa precisão, com desvios-padrão relativos inferiores a 3,3\%. A concentração de urânio variou de 40,8 a 101,1 $\mu \mathrm{g} \mathrm{kg}^{-1}$ (base seca) nas amostras de mexilhão analisadas. A comparação entre as concentrações de U obtidas nos mexilhões dos pontos de transplante indicou que a região de Santos possui a maior e a menor concentração de U, dependendo do período de exposição das amostras de mexilhão.
\end{abstract}

Palavras-chave: análise por ativação com nêutrons epitérmicos, mexilhão Perna perna, urânio.

\section{ABSTRACT \\ Determination of uranium in samples of Perna perna mussel transplanted along the São Paulo seashore, by epithermal neutron activation analysis (ENAA)}

Bivalve mussels are being used in many studies, for biomonitoring purposes, in coastal regions, due to their capacity of accumulating pollutants. This paper presents the results obtained for uranium determinations in samples of mussels of the Perna perna species (Linnaeus, 1758), transplanted along the northern seashore of the State of São Paulo, Brazil. Mussels produced at a cultivation site in the Cocanha Beach, in Caraguatatuba (control site) were transplanted, in all seasons of the year, to four different sites: Engenho d'Água Beach, in Ilhabela; Almirante Barroso Terminal (TEBAR), in São Sebastião; e Palmas Island and Itaipu, in the Santos Bay. For uranium determination, the method of epithermal neutron activation analysis (ENAA) was used and for analytical quality control the reference materials NIST SRM 1566b Oyster Tissue and NIST SRM 1575 Pine Needles were used. The results obtained in these materials were in good agreement with the certified values (percentages of error less than 2.2\%) and presented good precision (relative standard deviations below 3.3\%). The uranium concentrations in mussel samples varied from 40.8 to $101.1 \mathrm{\mu g} \mathrm{kg}^{-1}$ (dry weight). The comparison among the uranium concentrations obtained in the different sites of transplantat indicated that the region of Santos has the highest and the lowest concentration of $U$, depending on the period of exposure of the samples of mussels.

Key words: epithermal neutron activation, Perna perna mussel, uranium.

*Corresponding author: Daniele Seo, e-mail: danyseo@uol.com.br. 


\section{INTRODUÇÃO}

Nas últimas décadas, os ecossistemas aquáticos têm sido fortemente alterados em função de múltiplos impactos ambientais decorrentes de atividades antrópicas, como: o escoamento de esgoto proveniente de áreas urbanas, a liberação de diversos produtos químicos (orgânicos e inorgânicos) pela atividade industrial, a agricultura e o fluxo de embarcações, atividade a partir da qual podem ocorrer vazamentos acidentais de petróleo e derivados, combustíveis e outros produtos transportados por via marítima (Kennish, 1991). Consequentemente, os ecossistemas aquáticos podem acabar perdendo suas características naturais e sua diversidade biológica.

Neste contexto, um dos meios para determinar as concen-trações dessas substâncias tóxicas em água do mar é a monito-ração por meio de diferentes espécies de bivalves, que têm sido utilizados por diversos pesquisadores em várias regiões do Brasil e do exterior.

O uso de mexilhões no biomonitoramento da contami-nação marinha proporciona uma estimativa da disponibilidade de elementos-traço à biomassa de diferentes áreas e localidades. Esses animais representam um dos grupos de organismos aquáticos mais estudados em programas de biomonitoramento (Silva et al., 2001; Lionetto et al., 2003) e em estudos toxicológicos (Valbonesi et al., 2003; Corsi et al., 2003). As vantagens mais evidentes da utilização desses organismos são sua ampla distribuição geográfica, hábito séssil e habilidade de concentrar compostos químicos em até $10^{2}-10^{5}$ vezes em relação às concen-trações detectadas na água (Sunila, 1987). Nesse sentido, esses organismos podem bioacumular metais e diversos compostos químicos, orgânicos e inorgânicos, incorporando-os na cadeia trófica e atingindo grande parte dos diferentes estratos que constituem os ecossistemas aquáticos (Viarengo, 1989). Esses moluscos são capazes de acumular poluentes de modo seden-tário, sem causar sua morte (Yusof et al., 2004).

No Brasil, diversos trabalhos têm sido realizados visando ao uso de organismos marinhos, como os mexilhões, como indicadores de metais tóxicos e compostos organoclorados. Ênfase especial é dada à análise de mercúrio e metilmercúrio, por conta da particular toxicidade dos compostos orgânicos desse elemento e das descargas industriais que ocorrem, particularmente das indústrias de cloro-alcális (Furley \& Oliveira, 1998; Callil, 1998).

Semmler (2007) determinou os elementos As, Ca, Co, Cr, $\mathrm{Fe}, \mathrm{Na}, \mathrm{Pb}, \mathrm{Se}$ e $\mathrm{Zn}$ em amostras de mexilhões Perna perna do litoral do Estado de São Paulo, após período de exposição em pontos sujeitos a contaminação, pela técnica de análise por ativação com nêutrons instrumental (INAA), e os elementos $\mathrm{Cd}, \mathrm{Hg}$ e $\mathrm{Pb}$, pelo método de espectrometria de absorção atômica (AAS). Foi verificado que, após os transplantes dos mexilhões para os pontos de estudo, aumentaram as concentrações de todos os elementos estudados, indicando assim a boa aplicabi-lidade do mexilhão Perna perna como biomonitor.

A partir desse trabalho, julgou-se de grande interesse fazer também um estudo sobre a avaliação do elemento urânio em mexilhões do litoral norte do Estado de São Paulo. O urânio de distintas origens, dentre as quais podemos destacar os resíduos industriais, agrícolas e de mineração, é levado pelos rios para o oceano, contribuindo para o aumento da concentração desse elemento em regiões costeiras. Poucos trabalhos analisam o urânio nos mexilhões para fins de biomonitoramento (Akyil \& Yusof, 2007). Entretanto, as determinações de radioisótopos desse elemento, principalmente de ${ }^{238} \mathrm{U}$, têm sido realizadas por diversos pesquisadores (Alvarez \& Sánchez, 1999; Markich, 2003; Bettinelli et al., 2004; Cuculic et al., 2005) devido à importância em estimar o risco de ingestão de alimentos contendo isótopos radioativos de urânio e de seus descendentes.

Neste sentido, o objetivo deste estudo foi avaliar a con-centração de urânio em amostras de mexilhão Perna perna para investigar possível contaminação do litoral do Estado de São Paulo.

Para determinação do urânio em materiais biológicos, diversas técnicas têm sido utilizadas, como a espectrometria de massa com fonte de plasma acoplado indutivamente (Igarashi et al., 1989), espectrofotometria com arsenazo III (Akyil \& Yusof, 2007) e análise por ativação com nêutrons (Zikovsky, 2005). $\mathrm{Na}$ literatura, não foi encontrado nenhum estudo compa-rativo sobre as vantagens entre essas técnicas para a determi-nação de $\mathrm{U}$ em materiais biológicos. No presente trabalho foi aplicada a técnica de AANE por sua disponibilidade de uso no laboratório. Essa técnica consiste na ativação do urânio das amostras com nêutrons epitérmicos (nêutrons com energia cinética de $0,5 \mathrm{eV}$ a $5 \mathrm{MeV}) . \mathrm{O}{ }^{239} \mathrm{~Np}$ formado da ativação do ${ }^{238} \mathrm{~Np}$ com nêutrons é medido para as análises quali e quantita-tivas. $\mathrm{O}$ uso da irradiação com nêutrons epitérmicos no lugar de nêutrons térmicos apresenta vantagem devido ao elevado valor da integral de ressonância do ${ }^{238} \mathrm{U}$ de 284 b. A vantagem da ativação com nêutrons epitérmicos na determinação de U é o aumento da sensibilidade como consequência da redução da atividade da matriz. As amostras de mexilhão apresentam altos teores de sódio e o ${ }^{23} \mathrm{Na}$ tem integral de ressonância relativamente baixa $(0,303 \mathrm{~b})$, tornando vantajoso o uso da ativação com nêutrons epitérmicos.

Os ensaios preliminares comprovaram a impossibilidade de utilizar a irradiação com nêutrons térmicos na determinação de $\mathrm{U}$ por conta da interferência de altos teores de sódio, da ordem de $37,80 \mathrm{mg} \mathrm{g}^{-1}$, presente nos mexilhões. A alta atividade do ${ }^{24} \mathrm{Na}$ formado na irradiação com nêutrons térmicos impediu a detecção do ${ }^{239} \mathrm{~Np}$.

\section{MATERIAL E MÉTODOS}

\section{Transplante, coleta e tratamento das amostras de mexilhão Perna perna}

As amostras de mexilhões Perna perna foram adquiridas em cultivo situado na Praia da Cocanha, em Caraguatatuba, considerada área de controle, e foram transplantadas para vários pontos ao longo do litoral paulista, sendo escolhidos os seguintes locais: píer sul da PETROBRAS (TEBAR), São Sebastião; Praia do Engenho d'Água, Ilhabela; Ilha das Palmas, Santos; e Ponta de Itaipu, Santos (Figura 1). Esses locais foram escolhidos por serem considerados pontos onde os organismos 
ficam sujeitos a situações de estresse devido à proximidade de aporte de efluentes industriais, efluentes municipais ou ativi-dades ligadas à indústria do petróleo. Decorridos os três meses, ou seja, uma estação do ano, os mexilhões foram coletados para análise e nesses pontos foram realizados novos transplantes para monitoração do próximo período.

Em cada ponto de coleta foi colocada uma corda do cultivo sobre a qual os mexilhões ficavam presos. Na coleta das amostras de mexilhão Perna perna foram selecionados 90 mexilhões de tamanhos distintos: 30 de tamanhos pequenos (largura 1,5 $\pm 0,5 \mathrm{~cm}$ e comprimento $3,5 \pm 0,5 \mathrm{~cm}$ ), 30 médios (largura 3,0 $\pm 0,5 \mathrm{~cm}$ e comprimento $5,0 \pm 0,5 \mathrm{~cm}$ ) e 30 grandes (largura 4,5 $\pm 0,5 \mathrm{~cm}$ e comprimento $6,5 \pm 0,5 \mathrm{~cm}$ ), considerando-se o tamanho da concha. Em seguida, retiraram-se algas e outros organismos que ficam impregnados nas conchas dos mexilhões utilizando uma faca de lâmina de titânio. Após a remoção das cracas, os organismos foram lavados com água do mar, e o comprimento e largura das conchas foram medidos. Os tecidos dos mexilhões retirados das conchas foram tri-turados e homogeneizados em um liquidificador com lâminas de titânio. Ao término da homogeneização, essas amostras, colocadas em potes de plástico, foram pesadas, armazenadas e congeladas em freezer para posterior secagem usando um liofilizador de marca Thermo Electron Corporation, modelo Modulyo D-115, por um período de 48 horas, à temperatura de $-52^{\circ} \mathrm{C}$ e pressão de 74 $\mu$ bar. As amostras secas foram de-pois moídas em almofariz de ágata e peneiradas utilizando uma peneira de poliéster de 100 mesh. Finalmente, as amostras na forma de pó foram armazenadas em frascos plásticos, eti-quetadas e guardadas em freezer para posteriores análises. Na ocasião da pesagem dessas amostras de mexilhão para análise, foram novamente feitas as determinações de umidade, secando alíquota de cada amostra numa estufa por 24 horas a $85^{\circ} \mathrm{C}$. As percentagens médias da perda de água após lio-filização e secagem na estufa foram de $83,4 \%$ e $7,1 \%$, respecti-vamente.

\section{Análise dos materiais de referência certificados}

Para avaliar a qualidade dos resultados analíticos, foram analisados os materiais de referência certificados NIST SRM 1566b Oyster Tissue e NIST SRM 1575 Pine Needles, proce-dentes do National Institute of Standards and Technology, EUA. Para expressar os resultados dessas análises na base seca foram feitas as determinações de perda de umidade, secando os materiais a $85^{\circ} \mathrm{C}$ por 24 horas. Nessas secagens, foram obtidas porcentagens de perda de umidade de 3,7\% e 7,1\% para NIST 1566b Oyster Tissue e NIST 1575 Pine Needles, respecti-vamente.

\section{Preparação do padrão sintético de urânio}

Para a preparação do padrão sintético de U foi utilizada uma solução padrão certificada desse elemento adquirida da Spex CertiPrep, EUA. A partir dessa solução padrão estoque, foi preparada uma solução mais diluída com a concentração de $80 \mu \mathrm{g} \mathrm{mL}^{-1}$. Pipetaram-se $50 \mu \mathrm{L}$ dessa solução sobre tiras de papel de filtro Whatman $\mathrm{n}^{\mathrm{o}} 40$, as quais foram colocadas no dessecador para a secagem da alíquota pipetada à temperatura ambiente. Posteriormente, essas tiras foram dobradas e colocadas em invólucros de polietileno. Os plásticos para a confecção desses invólucros eram previamente lavados com solução diluída de ácido nítrico p.a. e água purificada. A massa do U nesse padrão sintético foi de $4,0 \mu \mathrm{g}$.

\section{Procedimento da análise por ativação com nêutrons epitérmicos (AANE)}

Cerca de $200 \mathrm{mg}$ de cada amostra de mexilhão e de materiais de referência certificados pesados em invólucros de polietileno foram irradiados no reator IEA-R1 do IPEN-CNEN/ SP juntamente com o padrão sintético de U. Para irradiação com nêutrons epitérmicos, as amostras de mexilhão, os materiais de referência e o padrão de U individualmente embalados em folha de alumínio foram colocados no interior de uma cápsula de cádmio e este no dispositivo de alumínio para irradiação.

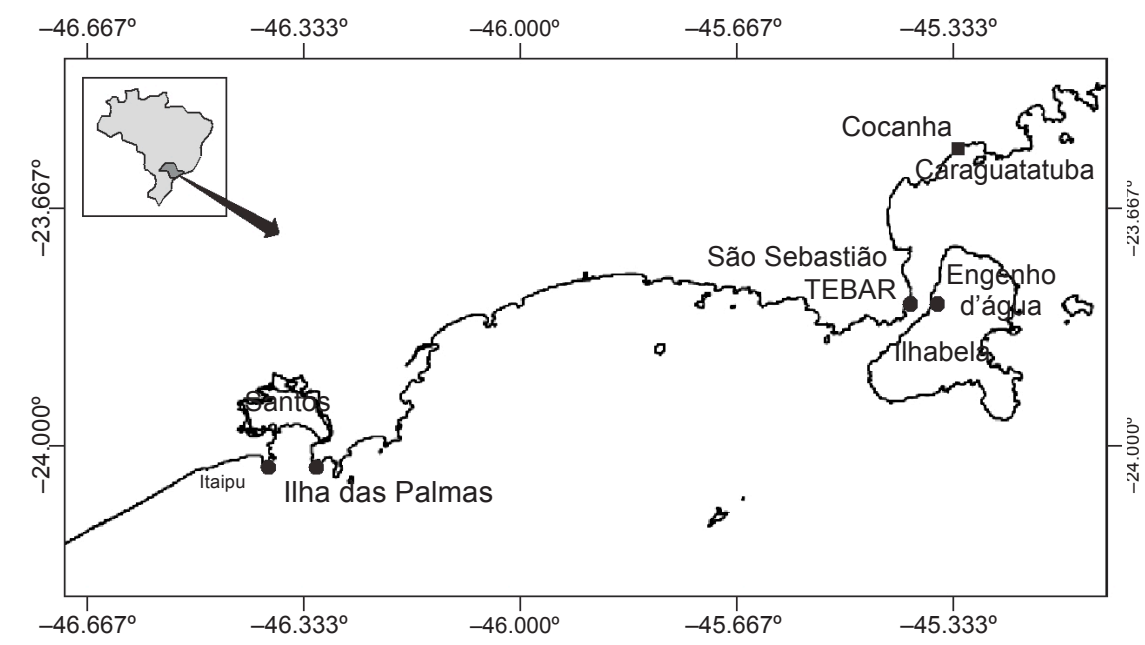

Figura 1 - Locais de amostragem na região costeira de São Paulo, Brasil. 
As irradiações foram realizadas por um período de 16 horas sob um fluxo de nêutrons térmicos da ordem de $5,0 \cdot 10^{12}$ $\mathrm{n} \mathrm{cm}^{-2} \mathrm{~s}^{-1}$. Após aproximadamente seis dias de decaimento, as amostras e padrões foram individualmente montados em suportes de aço inoxidável para as medições das atividades gama que foram feitas usando um detector de Ge hiperpuro modelo GC2018 ligado a um analisador de espectro digital DSA 1000, ambos da marca Canberra. Os tempos de medição foram de 1 hora para o padrão e de 15 horas para as amostras.

Para aquisição dos espectros gama e para o seu processamento foram utilizados os programas Genie-2000 NAA e GAMA Acquisition \& Analysis da Canberra. O radioisótopo medido foi o ${ }^{239} \mathrm{~Np}$, formado segundo a reação nuclear:

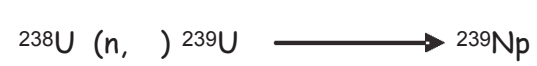

A meia-vida do ${ }^{239} \mathrm{~Np}$ é de 2,36 horas, e as energias dos raios gama utilizadas (em keV) foram: 106,12; 228,18; e 277,60. A concentração do $U$ foi calculada pelo método comparativo (De Soete et al., 1972). Foram realizadas duas determinações para todas as amostras de mexilhão.

\section{RESULTADOS E DISCUSSÃO}

Na Tabela 1 estão os resultados das concentrações de urânio obtidos na análise dos materiais de referência NIST SRM 1566b Oyster Tissue e NIST SRM 1575 Pine Needles, juntamente com os valores dos certificados (NIST, 1993; NIST, 2001).

A comparação dos resultados obtidos com os valores dos certificados indica boa concordância, mostrando que o procedimento de análise por ativação aplicado é adequado para a análise do elemento urânio. Os erros relativos percentuais obtidos foram inferiores a $2,2 \%$, e os desvios-padrão relativos (DPR) dos resultados foram inferiores a 3,3\%.

Os resultados de concentração de U obtidos também foram submetidos a controle estatístico calculando os valores de $\mathrm{z}$-score ou de diferença padronizada (Bode, 1996). Os valores obtidos de $\mid z$-score $\mid<2$ indicam que os resultados estão dentro da faixa dos valores do certificado em um nível de confiança de $95 \%$.
Na determinação de U nos mexilhões, foram também calculados os limites de detecção segundo o critério de Currie (Currie, 1968). Esses valores de limite na base seca das amostras variaram de 11,5 a $23,9 \mu \mathrm{g} \mathrm{kg}^{-1}$, indicando alta sensibilidade da técnica ENAA.

Os resultados das análises dos mexilhões obtidos na base seca para diferentes tempos de exposição são apresentados na Figura 2. Esses resultados indicam que o $U$ está presente nos mexilhões em concentrações baixas, da ordem de $\mu \mathrm{g} \mathrm{kg}^{-1}$.

Por outro lado, segundo o trabalho de Zikovsky (2005), que analisou as concentrações de urânio em uma grande variedade de alimentos consumidos em Quebec, Canadá, as maiores concentrações obtidas foram em moluscos. No caso dos demais alimentos, as concentrações de urânio estiveram quase sempre abaixo do limite de detecção do método.

Os valores obtidos para a concentração de urânio foram comparados usando-se análise de variância de fator único ANOVA, teste de Tukey; Programa Origin, versão 7.5 (Vieira, 1997). Para uma análise sazonal, foi observado um aumento na concentração de U após o transplante, para a estação do inverno em um nível de confiança de 95\%; a acumulação desse elemento apresentou uma diferença significativa em relação ao controle (Cocanha), nos pontos do TEBAR, Ilhabela e Itaipu. Para a estação do verão, pode-se afirmar que houve diminuição significativa na concentração de U para os pontos de Ilhabela e Ilha das Palmas após o transplante em um nível de confiança de $95 \%$.

As concentrações de U observadas variaram de 7,7 a 18,8 $\mu \mathrm{g} \mathrm{kg}^{-1}$, em base úmida. Esses valores podem ser conside-rados altos se comparados aos resultados obtidos para alimen-tos de origem não marinha, pois o maior teor de $U$ encontrado foi $\mathrm{em}$ feijão, com 11,07 $\mu \mathrm{g} \mathrm{kg}^{-1}$ (Garcia et al., 2006). As concen-trações de $U$ nos mexilhões analisados, na base seca, variaram de 40,8 a $101,1 \mu \mathrm{g} \mathrm{kg}^{-1}$. Comparando esses resultados com os da literatura para os alimentos marinhos, verifica-se que os dados obtidos são da mesma ordem de grandeza daqueles obtidos para ostras de 31 a 59 $\mu \mathrm{g} \mathrm{kg}^{-1}$ (Zikovsky, 2005). Entre-tanto, as concentrações obtidas no presente trabalho foram inferiores às concentrações obtidas para mexilhão de 1930 a $2820 \mu \mathrm{g} \mathrm{kg}^{-1}$ e para ostra de 2030 a $2050 \mu \mathrm{g}$ $\mathrm{kg}^{-1}$ (Akyil, 2007).

Tabela 1 - Concentrações de urânio em $\mu \mathrm{g} \mathrm{kg}^{-1}$, nos materiais de referência certificados.

\begin{tabular}{|c|c|c|c|c|c|}
\hline \multirow{2}{*}{ Materiais de referência certificados } & \multicolumn{4}{|c|}{ Este trabalho } & \multirow{2}{*}{$\begin{array}{l}\text { Valores dos } \\
\text { certificados }\end{array}$} \\
\hline & Média \pm DP & DPR $\%$ & $\mathrm{Er}^{\mathrm{C}} \%$ & $z_{\text {score }}$ & \\
\hline NIST SRM 1566b Oyster Tissue & $260,7 \pm 5,6$ & 2,2 & 2,2 & 1,95 & $255,0 \pm 1,4$ \\
\hline NIST SRM 1575 Pine Needles & $20,3 \pm 0,7$ & 3,3 & 1,3 & 0,05 & $20,0 \pm 4,0$ \\
\hline
\end{tabular}

${ }^{a} \mathrm{DP}=$ desvio-padrão; ${ }^{b} \mathrm{DPR}=$ desvio-padrão relativo; ${ }^{\mathrm{c}} \mathrm{Er}=$ erro relativo. 


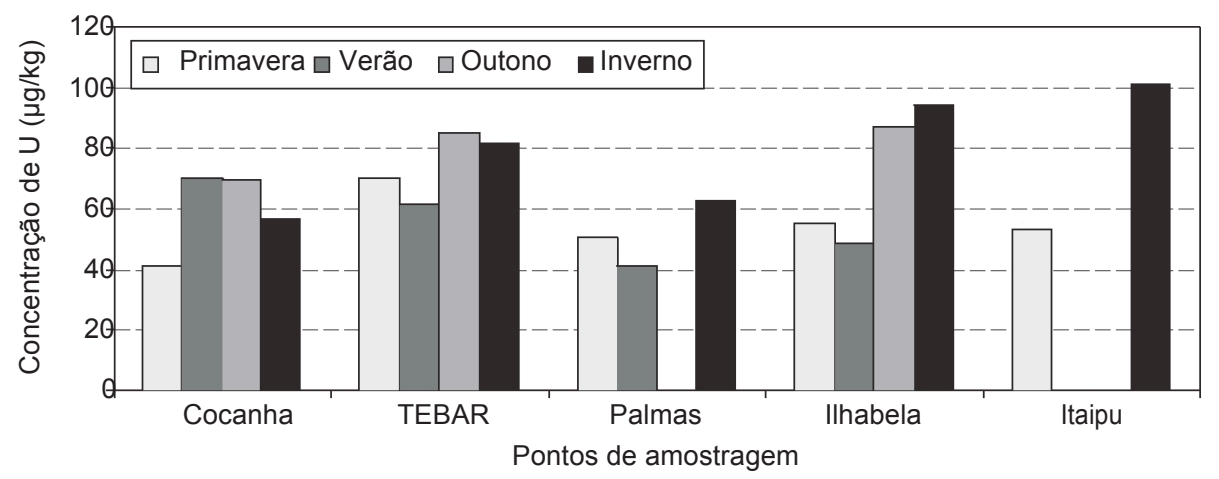

Figura 2 - Concentrações de urânio nas amostras de mexilhão na base seca para diferentes pontos de exposição.

\section{CONCLUSÃO}

Com base nos resultados obtidos, pode-se concluir que o método de análise por ativação com nêutrons epitérmicos mostrou-se eficaz na determinação de urânio. Os resultados obtidos nos materiais de referência foram concordantes com os valores dos certificados, indicando boa exatidão, já os dados obtidos indicaram boa precisão.

De acordo com os resultados obtidos podemos concluir que o mexilhão Perna perna é um bom biomonitor para a deter-minação de urânio.

Agradecimentos - Os autores agradecem à CNPq e à FAPESP, pelo apoio financeiro concedido em projetos de pesquisa e pela bolsa PIBIC/CNPq, e ao Centro do Reator de Pesquisas (CRPq), pela irradiação das amostras.

\section{REFERÊNCIAS BIBLIOGRÁFICAS}

AKYIL, S. \& YUSOF, A. M., 2007, The distribution of uranium and thorium in simples taken from diferent polluted marine environment. J. Hazardous Mat., 144: 564-569.

ALVAREZ, M. J. R. \& SÁNCHEZ, F., 1999, The transfer of uranium from sediment to water along Jucar River, Spain. J. Radioanal. Nucl. Chem., 242: 297-307.

AUGUSTSON, J. H.; HAYNES, J. W. \& SANDERS, T. W., 1980, The determination of uranium in biological materials by neutron activation analysis using the fission product. J. Radioanal. Chem., 60: 373-383.

BETTINELLI, M.; SPEZIA, S. \& MINOIA, C., 2004, Analysis of uranium and isotopic ratio measurement in fish and marine invertebrates from the North Adriatic Sea by inductively coupled plasma mass spectrometry. Rapid Commun. Mass. Spectrom, 18: 465-468.

BODE, P., 1996, Instrumental and organizational aspects of a neutron activation analysis laboratory. $\mathrm{Ph}$. D. Thesis, Delft University of Technology, The Netherlands.

CALLIL, C. T., 1998, Utilização de moluscos como indicadores de mercúrio: proposta de biomonitoração. In: $5^{o}$ ECOTOX - Encontro Brasileiro de Ecotoxicologia. Itajaí, Santa Catarina.

CORSI, I.; MARIOTTINI, M.; SENSINI, C.; LANCINI, L. \& FOCARDI, S., 2003, Fish as biomarkers of brackish ecosystem health: integrating biomarker responses and target pollutant concentrations. Oceanol. Acta, 26: 129-138.

CUCULIC, V.; CUKROV, N.; BARISIC, D. \& MLAKAR, M., 2005, Uranium in sediments, mussels (Mytilus sp.) and seawater of the Krka river estuary. J. Environ. Radioact., 85: 59-70.
CURRIE, L., 1968, Limits for qualitative detection and quantitative determination. Anal. Chem., 40: 586-593.

DE SOETE, D.; GIJBELS, R. \& HOSTE, J., 1972, Neutron activation analysis. Wiley-Interscience, New York, $249 \mathrm{p}$.

FURLEY, T. H. \& OLIVEIRA, A. C., 1998, Monitoramento do efluente da Aracruz Celulose S/A através do uso de mexilhões como indicadores de metais pesados e organoclorados. In: $5^{\circ}$ ECOTOX - Encontro Brasileiro de Ecotoxicologia, Itajaí, Santa Catarina.

GARCIA, F.; BARIONI, A.; ARRUDA-NETO, J. D. T.; DEPPMAN, A.; MILIAN, F.; MESA, J. \& RODRÍGUEZ, O., 2006, Uranium levels in the diet of São Paulo City residents. Environ. Int., 32: 697 - 703 .

KENNISH, M. J., 1991, Ecology of estuaries: anthropogenic effects. CRC Press, Boca Raton, 494 p.

LIONETTO, M. G., CARICATO, R., GIORDANO, M. E., PASCARIELlO, M. F., MARINOSCI, L. \& SCHETTINO, T., 2003, Integrated use of biomarkers (acetyl cholinesterase and antioxidant enzymes activities) in Mytillus galloprovincialis and Mullus barbatus in an Italian coastal marine area. Mar. Pollut. Bull., 46: 324-330.

MARKICH, S. J., 2003, Influence of body size and gender on valve movement responses of a freshwater bivalve to uranium. Environ. Toxicol., 18: 126-136.

NIST, NATIONAL INSTITUTE OF STANDARDS AND TECHNOLOGY, 1993, Standard Reference Material 1575 Pine Needles. Certificate from National Institute of Standards and Technology. USA, p. 1-4.

NIST, NATIONAL INSTITUTE OF STANDARDS AND TECHNOLOGY, 2001, Standard Reference Material 1566b Oyster Tissue. Certificate from National Institute of Standards and Technology. USA, p. 1-8.

SEMMLER, M. G. M. C., 2007, Biomonitoração de $\mathrm{Hg}, \mathrm{Cd}$, Pb e outros elementos em áreas costeiras do Estado de São Paulo por meio do mexilhão transplantado Perna perna (Linnaeus, 1758). Tese de Doutorado, Instituto de Pesquisas Energéticas e Nucleares, São Paulo.

SILVA, C. A. R., RAINBOW, P. S., SMITH, B. D. \& SANTOS, Z. L., 2001, Biomonitoring of trace metal contamination in the Potengi estuary, Natal (Brazil), using the oyster Crassostrea rhizophorae, a local food source. Water Res., 35: 4072-4078.

SUNILA, I., 1987, Histopathology of mussels (Mytilus edulis L.) from the Tvärminne area, the Gulf of Finland (Baltic Sea). Ann. Zool. Fenn., 24: 55-69.

VALBONESI, P., SARTOR, G. \& FABBRI, R., 2003, Characterization of cholinesterase activity in three bivalves inhabiting the North Adriatic Sea and their possible use as sentinel organisms for biosurveillance programmes. Sci. Total Environ., 312: 79-88. 
VIARENGO, A., 1989, Heavy metals in marine invertebrates: mechanisms of regulation and toxicity at the cellular level. Rev. Aquat. Sci., 1: 295.

VIEIRA, S., 1997, Introdução à bioestatística. Campus, Rio de Janeiro, $131 \mathrm{p}$

YUSOF, A. M.; YANTA, N. F. \& WOOD, A. K. H., 2004, The use of bivalves as bio-indicators in the assessment of marine pollution along a coastal area. J. Radioanal. Nucl. Chem., 259: 119-127.
ZIKOVSKY, L., 2005, Determination of uranium in food in Quebec by neutron activation analysis. J. Radioanal. Nucl. Chem., 267: 695-697. 